times there was a rash of some kind, generally erythema or urticaria, with troublesome itching. In one case where there was urticaria there was loss of consciousness; and, taking into consideration that it was immediately restored by the hypodermic injection of atropine, it seems to me quite possible that there may have been urticaria of the hemispheres, a rare but recognised condition. In two cases buzzing of the ears was noticed. In two also there was violent gastric pain, followed by gastro-enteritis, lasting six weeks, it being several months before the patient entirely recovered. Once there was profound mental disturbance, the patient being afraid of becoming insane, and the mental equilibriam did not return entirely for some months. Hypersecretion in the shape of running from the nose and eyes and excessive perspiration were noted several times, and once the patient felt as if she were stuffed with ice.

Although I had not been in the least alarmed by my patient, who har never been in the slightest danger, and unly made known the case in the interests of truth, a somewhat sharp discussion followed, and a very eminent professor decided that his inexperienced confrè had been frightened at symptorns with which everyone was ac. quainted, referring to his brochure upon the subject where they were said to have been described. As a matter of fact, it was only mentioned that in some cases a rash appeared like that sometimes following the administration of quinine, but without gravity, and requiring no treatment - a very different picture to that which I bad drawn. The same professor rallied me pleasantly upon what he was pleased to term ny homoeopathic tendencies in prescribiug belladonna, supposing that I had done so on account of the "scarlatiniform" rash he had seen, whereas I was in reality suided in my choice by the fact that two of the communest symptoms of an overdose of antipyrin being hypersecretion and urticaria, the drug that best counteracts these might reasonably be hoped to neutralise the effects of a medicine that gives rise to them. The upshot of the discussion was that a medicine having such high official approbation could on no account be allowed to have any kind of drawbacks.

Since then numerous cases have been related to me from time to lime by people thinking that I was "against antipyrin," "f which I have taken no account, using it neither more nor less than before. The only difference I have made since publishing my paper, which, I think, shows that the drug in anestion is not invariably harmless, has been to begin al wys by small doses of the drug. I generally prescribe the first full dose to be taken in four instalments, and when I have tested the idiosyncrasy of the individual, I continne henceforth with ordinary doses, always keeping a look out for possible accidents. I have several times had reason to congratulate myself that, instead of a tablespoonful containiog ten or fifteen grains of the drug, I had begun with a teaspoonful every half hour until the tablespoonful had been taken.

Now to the object of my present letter. During the last month or so I have been compelled, like everyone else, to give antipyrin for the treatment of the prevailing epidemic, my practice having consisted of a sharp purge to begin with, antipyrin to relieve the pain, and quinine as the specific remedy for the disease. In many cases there have been eruptions, some of which were pathological, but others were decidedly of drug origin. I have seen discharges from the eyes and nose, and swelling of the eyelids. The only serious complication of the disease of a preventable kind (bronchopneumonia and pleurisy having been generally due to im. prudenct) has been pulnıonary paralysis, and, although I am wandering somewhat from the point, I have often found cough that had been attributed to bronchial irritation due to relaxey palate and nvula.

What I wish to point out, however, is that I find the symptoms put down to the influenza are in many cases those described in my paper as due to overdoses of antipyrin, particularly swelling of the eyes, urticaria, and watery discharges; and, conversing upon the subject recently with a member of the profession, I was told of a case terminating in death, and where, in my opinion, the fatal occurrence was distinctly due to treatment. The patient, an elderly American lady, had been treating herself. The symptoms had consisted of cough, a dusky eruption on the body, which appeared swollen, profuse perspiration, troublesome itching and urticaria, chiefly between the fingers, swelling of the eyelids, which were reduced to a mere slit, and fear of impending insanity. The antipyrin had been taken for about ten lays, and persisted in, because the gravity of the symptoms, which included pains in the limbs and prostration, seemed to point to the necessity of active treatment. Finally, a medical man was called in and the antipyrin stopped, but the patient never rallied, and died two days later.

Antipyrin is one of the most valuable additions to the Pharmacopocia of modern times, and no one can call in question our indebtedness to it during the late epidemic: but I would submit that some of the supposed symptoms put down to the influenza are really due to the action of: the remedy; and $[$ feel sure that if the attention of the profession is called to this point, niy statements will be endorsed by many othexs.-I am, Sirs, yours truly,

Rue Marbeuf, Paris, Jan. 1890.

OSCAR JENNINGS, M.D.

\section{A SENSITIVE AND CONVENIENT TEST FOR ALBUMEN IN URINE.}

To the Editors of THE LANCET.

SIRs, - I have been for some years seeking a really trust. worthy and, at the same time, convenient test for albuner in urine; and after a long series of experiments I am glad to be able to say that I think all the requirements of the busy clinical practitioner, as well as those of the more leisurely laboratory chemist, will be found to be satisfied by the trichloracetic acid introduced by M. Boymond in November last. This crystalline body can be carried in a small bottle, and all that is necessary to apply the test is to drop a fras. ment into a little of the urine in a test tube. There is no doubt about the reaction obtained, because the trichloracetic acid does not throw out peptones like the potassio-mercuric iodide, or coagulate mucin like so many other "tests." The white cloud caused by albunien is produced with distinctness when the albumen is present in only very smal quantity, and it varies in density with the amount. Meanwhile, peptones are not, as I have said, deposited, and there is no need to counter-check the experiment by heat. It will be a great boon to practitioners to possess so delicate ance trustworthy a means of recognising albumen in urine, with a. test easily carried in the waistcoat pocket.

I am, Sirs, yours faithfully, Hanover-square, W., Jan. 1890. J. MORTIMER GRANyILLE.

\section{TESTS FOR COLOUR-BLINDNESS}

\section{To the Editors of TIIE LANCET.}

SIRS,--I see mention in a recent issue of THE LANCET of a test for colour-blindness by Mr. St. Clair Buxton, and gather therefrom that it is some test with coloured glasses.

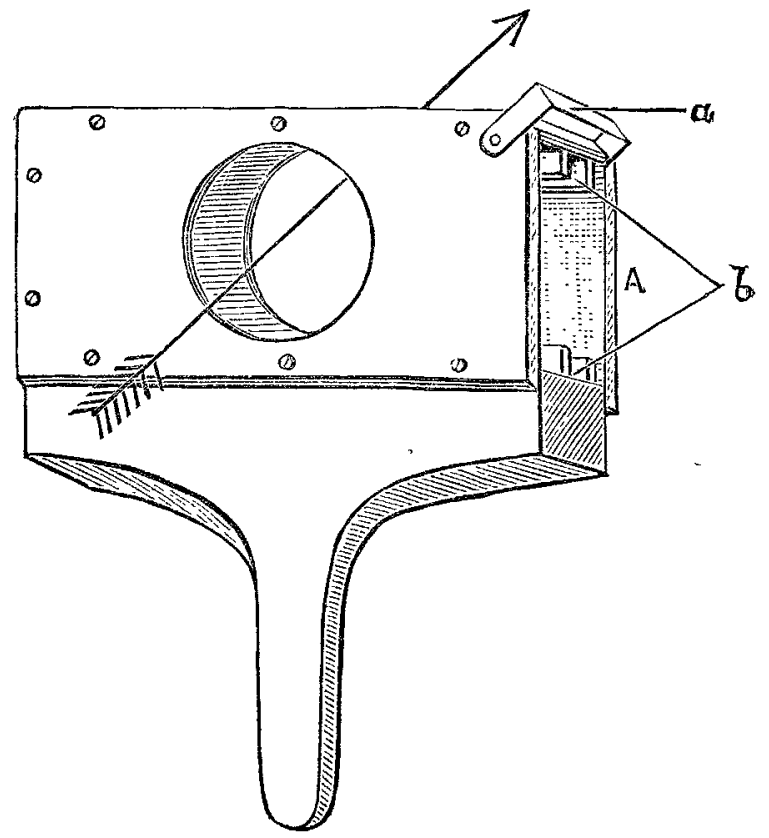

$a$, Catch for holling glasses. $b$, Grooves.

For some time I have been testing the sight of my Midland Railway men with coloured glasses after the following plan :-I have a sort of flat box, with a handle below (vide diagram), the box being open at $A$ and grooved along the 